\title{
Opportunity and overview of SMS-based e-government in developing countries
}

\author{
T. D. Susanto \& R. Goodwin \\ School of Informatics and Engineering, \\ The Flinders University of South Australia
}

\begin{abstract}
Despite the large number of e-government initiatives in developing countries, most of the initiatives have failed. Possible causes of the failures include: low Internet penetration, high Internet costs and Internet illiteracy. Rather than forcing citizens to upgrade their current devices and knowledge by promoting e-government through PCs and Internet access, this paper proposes a bottom-up development approach utilising the currently popular communications technology in developing countries, mobile phones and the Short Message Service (SMS) application.

The advantages of initially using SMS to deliver e-government services in developing countries include: a large number of users with appropriate skills, low cost as users already have mobile phones, and an adequate infrastructure. For these reasons SMS-based e-government can be utilised by more people in developing countries than Internet-based e-government.

This paper focuses on the potential of SMS-based e-government in low and lower middle-income countries (as defined by World Bank indicators). It includes an analysis of the present applications of SMS-based e-government in some of these countries.
\end{abstract}

Keywords: SMS, e-government, developing countries.

\section{Developing countries and e-government}

Developing countries have many economic, political and societal problems, which are exacerbated by their low per capita incomes. The system of government is considered to be one of the main causes of the problems.

Learning from developed countries, developing countries believe that using Information and Communications Technologies (ICT) to implement 
e-government has the potential to address the key barriers and challenges to achieving good governance. They believe e-government has the potential to boost efficiency, to enable new and improved services, to increase citizen participation and to create transparency. E-government is seen not just as tool or technology, but as a vehicle to deliver cultural change and a transformation that forces government to be transparent, efficient, accountable and improve services (Ndou [1]). The G8 Task Force on Digital Opportunities and the UN Task Force on ICT Access (Digital Opportunity Task Force 2002 in Ndou [1]) have identified e-government as one of the priorities based on the decisive role it would play for ICT accessibility. Consequently, e-government initiatives have flourished in many developing countries such as Indonesia, Brazil, India, Chile, Argentina and the Philippines.

Despite the high number of e-government initiatives in developing countries most have failed. A survey by Heeks [2] regarding the success and failure rates of e-government in developing and transitional countries, found that more than one-third of initiatives are total failures; half can be considered to be partial failures; and only about one-seventh are successful.

Heeks [2] analysis showed that one of the critical failure factors of e-government projects is unrealistic design for the local environment. All e-government models implemented in developing countries, such as the Gartner model (Backus [3]), the Universal Access Model, the Broadcasting/WiderDissemination Model, the Interactive Service Model and the Comparative Analysis Model (Digital Governance [4]), use the Internet as the base medium in all their phases. They recommend governments build an Internet infrastructure and urge people to use the Internet medium to access the system, even though it's found that low Internet penetration, high Internet cost and Internet illiteracy still exist in developing countries. Internet illiteracy in African countries is not just limited to the uneducated people, there are a lot of university graduates and many office workers who have never used the Internet (Chivhanga [5]).

In terms of the Internet cost, The Directorate General for Research, European Parliament [6] has found that typical Internet costs for developing countries still far exceeds levels that would permit popular use. For example, the cost of leasing a high-capacity line from a service provider would be around $\$ 3,800$ in the USA, but about $\$ 180,000$ in Argentina. The effective line charge translates to a cost that often exceeds the average per capita income of many developing countries. As result, Accenture [7] found that the use of e-government in developing countries is low, (11\% on average).

Also the power supply is often intermittent in developing countries rendering unreliable any system dependent on mains power.

This paper examines the potential of SMS as an appropriate starting medium for delivering e-government services rather than the Internet medium by comparing Internet and SMS services in the poorer countries, classified as Low Income and Lower Middle Income in terms of GDP per capita by the World Bank. These countries represent half of the 189 member states of the International Telecommunication Union (ITU). 


\section{Provision of e-government services}

There is a direct correlation between Internet penetration and e-government usage: the higher the penetration, the higher the usage (Accenture [7]). Based on survey data of Internet penetration by Internet World Statistics [8], Internet penetration in developing countries is very low, $(4.07 \%$ of the population on average). By comparison, Internet penetration in developed countries, such as the 25 members of the European Union, has reached $49.3 \%$ of the population on average. How do you provide e-government services to most of the population of developing countries when they have never used or had access to the Internet?

Proposals to address the problem include: getting people involved by providing learning centres or Internet training programs, building many Internet kiosks, and developing Internet infrastructures. The focus is on an Internet and PC-centric environment for delivering the e-government services, but there are good reasons why the effort should be put into developing mobile centric e-government using SMS applications. As Andile Ngcaba, the director general in South Africa's department of communications, pointed out there are already 14 million cell phones in use in South Africa while only three million people have access to the Internet via PCs and the culture of using SMS is already widespread. Many companies already use SMS for business purposes and people routinely send each other SMS greeting cards. He believes that mobile telephones and SMS messages can become important vehicles for government information services (Epiphany [9]). A more sensible goal is to determine how best to use currently widely used technology as the starting point for development of e-government services. The answer to that question turns out to be remarkably clear: by promoting the spread not of PCs and the Internet, but of mobile phones and SMS applications.

\section{SMS-based e-government services in developing countries}

There are three reasons why utilizing SMS seems the logical approach for delivering e-government services in developing countries rather than the Internet: the number of SMS users is much higher, the SMS infrastructure is more extensive and the SMS price compared to the Internet is much lower.

\subsection{The SMS user}

In the world, including developing countries, mobile phone penetration is much higher than Internet penetration. ITU research [10] shows that since the year 2000 Internet penetration has grown at a slower rate than mobile penetration (see Figure 1). In 1985, most developing countries had virtually no mobile telephony, but by 1999 a number of these countries had more mobile subscribers than fixed-line subscribers (ITU 2000 in Fink et al. [11]).

SMS usage is linked to mobile phone use. Baskerville [12] notes that SMS usage increases as the number of mobile phone subscribers increases. A study by Mobinet [13] supports this analysis by showing that SMS has reached 
mass-market penetration in some countries. Across the 14 countries studied, 35\% of respondents reported using SMS at least once a day, with once-a-day usage $41 \%$ in Europe, $33 \%$ in Asia and 5\% in the U.S. A survey by the Yankee Group [14] shows that SMS users in the world will grow significantly from fewer than 17 million users in 2002 to nearly 70 million in 2007 , a penetration of $40 \%$ among wireless users in five years.

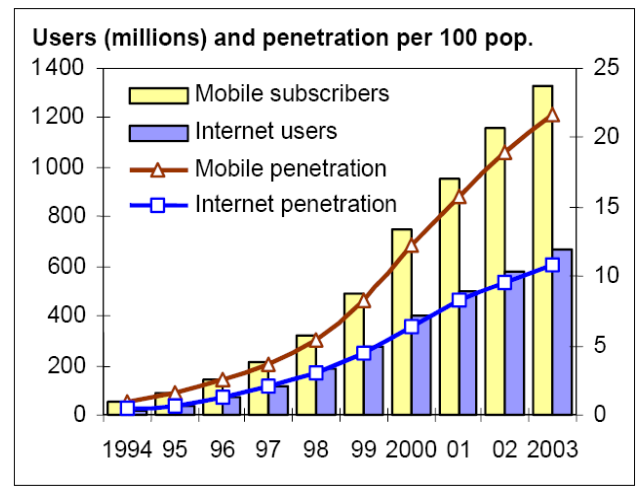

Figure 1: Comparison of Internet penetration and mobile penetration in the world (Source: ITU World Telecommunication Database).

In developing countries, the use of SMS is more popular and increasing more rapidly than Internet usage. A study by Burčík [15] claims that in Slovakia the frequency of using SMS is higher in places with a low Internet penetration. In the Philippines, SMS already dominates the traffic by a factor of 8 to 1 (SMS: Voice) with 50 million SMS messages per day (APRG [16]). In China SMS penetration is $76.8 \%$ with just $7.9 \%$ Internet penetration (China Mobile Limited [17]); moreover, India's SMS penetration is $50 \%$ with $3.6 \%$ Internet penetration (Chand [18]). Additionally, Hudson [19] states that the Internet users in developing countries are less than $15 \%$ of the world's Internet users, yet developing countries account for about $78 \%$ of the world's population. Most Internet users are in developed countries. In developing countries SMS has been used and accepted by more people than the Internet.

\subsection{The SMS price}

The low price of SMS in developing countries is one of the main reasons why people use SMS rather than the Internet. The cost of sending a standard SMS message in the highest price countries, such as Australia and New Zealand is US\$0.14 to US\$0.19 per message, but in some developing countries like India the cost is just US\$0.01 to US\$0.04 per message, China is US\$0.01 per message and Thailand is US\$0.04 to US\$0.08 per message Mobile Media [20].

By comparison, a study by Hudson [19] found that the Internet access pricing in developing countries is still expensive; particularly in African countries where 
the price of Internet access was higher than anywhere else in the world, and completely out of reach of most Africans. See Table 1.

Table 1: Internet access pricing.

\begin{tabular}{|l|c|c|}
\hline $\begin{array}{c}\text { Country } \\
\text { Classification }\end{array}$ & $\begin{array}{c}\text { Internet Access } \\
(20 \text { hours per month) }\end{array}$ & $\begin{array}{c}\text { Internet Price } \\
\text { (as \% of Gross National } \\
\text { Income /capita) }\end{array}$ \\
\hline Africa & $\$ 60.09$ & $241.3 \%$ \\
\hline Americas & $\$ 31.39$ & $27.5 \%$ \\
\hline Asia & $\$ 27.02$ & $48.7 \%$ \\
\hline Europe & $\$ 21.50$ & $6.8 \%$ \\
\hline Oceania & $\$ 39.84$ & $39.9 \%$ \\
\hline
\end{tabular}

(ITU December 2003, in Hudson [19]).

Comparing Internet access pricing between developing and developed countries, Rao [21] gave examples showing that the monthly Internet access charge is only $1.2 \%$ of average monthly income for a typical U.S. user, but $614 \%$ in Madagascar, 278\% in Nepal, 191\% in Bangladesh, and 60\% in Sri Lanka.

\subsection{Mobile phone and SMS Infrastructure}

A new report from the World Bank notes that $77 \%$ of the world's population already lives within range of a mobile phone network (Economist.com [22]). As a result SMS services in developing countries are increasing rapidly.

By comparison, the number of telephone lines and PCs, essential components of Internet infrastructure, is still low in developing countries (see Table 2) indicating that Internet access in developing countries is still very low (Hudson [19]). Further more, Hudson showed that high-income countries had 22 times as many telephone lines per 100 people than low-income countries and 96 times as many computers. The poorest countries have less than one computer and three fixed telephone lines per 100 people and most of these facilities are located in urban areas, so that rural access is virtually nonexistent.

Table 2: $\quad$ Internet infrastructures.

\begin{tabular}{|l|c|c|}
\hline \multicolumn{1}{|c|}{ Region } & $\begin{array}{c}\text { Main Tel Lines } \\
\text { /100 Pop }\end{array}$ & PCs/100 Pop \\
\hline Africa & 2.7 & 1.3 \\
\hline Americas & 34.8 & 29.0 \\
\hline Asia & 11.7 & 4.6 \\
\hline Europe & 36.6 & 21.4 \\
\hline Oceania & 39.1 & 42.4 \\
\hline World & 17.1 & 10.2 \\
\hline
\end{tabular}

(ITU December 2003, in Hudson [19]).

Hudson [19] stated that developing countries haven't provided suitable wireless bandwidth for Internet access; bandwidth is typically a maximum of 
9600 bits per second and often a little as 2400 bits per second, sufficient only for SMS and simple e-mail.

The current situation is that SMS has been accepted and used by many people in developing countries; SMS access prices are low; and the infrastructure supports widespread SMS usage. As the people have the necessary skills and access and the infrastructure is already in place, SMS can be considered to be appropriate medium for delivering e-government in developing countries.

\section{SMS-based e-government in developing countries}

Developing countries have already provided examples of e-government services by SMS. However, most of the initiatives are by one government department, there is no systematic and comprehensive national strategy for using SMS. Some SMS-based e-government initiatives in developing countries are outlined below.

\subsection{SMS for work}

In Kenya, people use a text messaging service to look for work. The job seeker registers with the service, then each time the system gets a new job advertisement an SMS vacancy alert is automatically sent to the job seeker's phone.

\subsection{SMS link to voters}

In South Africa, Patricia de Lille, the leader of the Independent Democrats, has launched an SMS service to keep in contact with her voters. Any member of the public can participate by sending messages or queries to her on topical national issues. SMS polls are conducted whereby South Africans can instantly vote on controversial subjects. The party also contacts voters by SMS, for example to organize a rally about a public issue.

\subsection{SMS for public convenience and public relations}

In June 2005, the Indonesian President Susilo Bambang Yudhoyono created an SMS hotline for complaining directly about red tape or inept officials; the line soon crashed as it was inundated by thousands of SMS text messages and calls.

In India, the government via mobile phone service providers sends SMSs to all subscribers regarding the date of implementation of new laws, such as the compulsory of wearing of helmets.

\subsection{SMS for public health care}

In 2005, Indonesia's Health ministry launched an SMS hotline to let the public report disease outbreaks and lodge complaints about health care using mobile phone text messages in an effort to get information as soon as possible.

\subsection{SMS for the environment}

In the Philippines, the TXTUSOK system lets citizens report vehicles emitting excessive smoke from their exhausts as part of the Clean Air law. Also, in 
Quezon, Philippines, citizens can communicate with their garbage collection services via SMS and report the need for an additional collection of rubbish in order to improve the efficiency of garbage collection.

\subsection{SMS for disaster warning}

Malaysia installed 313 automated measuring devices in critical areas to warn of flooding. These devices send a message to the central monitoring station which then warns citizens in crisis areas by SMS

\subsection{SMS for tax services}

In Sisli Municipality, Istanbul, Turkey, citizens can pay their taxes via SMS using their credit cards and ID numbers.

\subsection{SMS for fighting against crime}

In Manila, Philippines, citizens can report suspicious activities to police via SMS and receive SMS hints about increased crime in given areas.

\subsection{SMS for education}

SMS applications have been developed for education, such as at the De La Salle University, Manila. Via SMS students can find out whether their lesson is cancelled or get more information about dates/times of their tests, exams.

\subsection{SMS auctions}

In China, the SEO4 Mobile service provides an auction system for public. Via their mobile phone, bidders can join the auction by running a search using keywords and receive an MMS message with suitable products; then they can use SMS to place their bids.

All of these examples support the idea that SMS-based e-government services have a role in many developing countries.

\section{Limitation and advantages of SMS}

SMS has a number of limitations when compared to the World Wide Web. Each SMS message must be no longer than 160 alphanumeric characters and contain no graphics. Much of the information delivered by e-government contains graphics and more than 160 alphanumeric characters. An SMS-based e-government system cannot stand alone as an e-government system; it's an appropriate precursor of Internet use in developing countries.

As a messaging service SMS has several advantages:

- SMS messages are transmitted over the control channel using one signalling frame (160 bytes) not the bandwidth channels allotted to voice communication. Thus SMS is cheap and the cost remains constant throughout the day. 
- $\quad$ Sending an SMS is more polite and private.

- SMS doesn't interrupt receivers' work; they can decide when and where they will read and reply to a message.

- Unlike a pager, when an SMS message has been successfully sent an acknowledgement of receipt is sent to the sender.

These advantages of SMS ensure it will continue to be used.

\section{SMS-based e-government in the mobile Internet age}

The future of SMS based e-government will be directly affected by emerging technologies. In particular there will be a convergence of mobile phone and computer/internet technologies.

Mobile phones are becoming portable computers with most of the capabilities of current desktop computers. Built in cameras and screens allow mobile phone users to send and receive graphics and video as well as SMS and voice. Higher resolution cameras and screens will further enhance these capabilities. Voice input of text will reduce the need for full size keyboards. Developments in storage technology will further enhance their capabilities.

These new technologies will be supported by the development of wireless data transfer technology, such as the Wireless Application Protocol (WAP), and 3G and $4 \mathrm{G}$ networks. These new developments of wireless data transfer technology will provide the bandwidth needed.

Buckingham [23] believes that over time the nature of mobile communication, included messaging, is getting less textual and more visual, moving from text messages to icons and picture messages to photographs and blueprints to video messages and movie previews being downloaded and movie watching via data streaming on a mobile device. The key technologies underlying these new services and application are Enhance Messaging Service (EMS) and Multimedia Messaging Service (MMS). Supporting this analysis, Buckingham [24] said that SMS will probably be used in future, since the mobile phones, infrastructure, specifications, market development and awareness are in place today; but over time, as users connect to networks that offer more advanced data services and buy mobile terminals that support them, they will find it more convenient to receive all their emails rather than only a notification by SMS.

Thus an SMS-based e-government model such as the one proposed by the authors (Susanto and Goodwin [25]) will provide an appropriate cost effective pathway towards mobile e-government in developing countries.

As the range of services increases so too will the need for increased attention to security issues.

\section{Conclusions}

There are three major reasons for using SMS for e-government in developing countries instead of computers and the Internet: the large number of users with 
the necessary skills and access, the low cost, and the infrastructure is already in place. Such a system would be acceptable, affordable and operable.

Governments in developing countries should not force their citizens to upgrade their current devices and knowledge, but rather start with applications using current technologies and current bandwidth for information transfer by providing e-government services by SMS applications. Governments should start with the existing skills of its citizens, and the technologies available to them and plan for new technologies such as accessing the Internet using mobile devices in order to improve the service quality including content and data transfer rates.

SMS-based e-government can be a good starting point for delivering e-government services in developing countries, particularly as SMS services will continue to be used in the long term.

\section{References}

[1] Ndou V. (2004). E-government for Developing Countries: Opportunities and Challenges. The Electronic Journal on Information Systems in Developing Countries (EJISDC) No 18.

[2] Heeks, R. (2003). eGovernment for Development, University of Manchester, UK. Retrieved May 24, 2005, from http://www.egov4dev.org/.

[3] Backus, M. (2001). E-government in Developing Countries, IICD Research Brief-No 1 .

[4] Digital Governance. Generic Models. Retrieved October 15, 2005, from http://216.197.119.113/artman/publish/generic-models.shtml.

[5] Chivhanga, B.M. (2005, March). An Impact Assessment Model to Study the Diffusion of the Internet Africa. Retrieved September 29, 2005, from http:/www.globaledevelopment.org/papers/Internet\%20Impact $\% 20 \mathrm{in} \% 20$ AfricaTampereMarch2005.rtf.

[6] Directorate General for Research - Ueropean Parliament, (2001, March). Developing Countries and ICT Revolution, Luxemburg. Retrieved September 30, 2005, from http://www.europarl.eu.int/stoa/publi/pdf/0014-01 en.pdf.

[7] Accenture (2005, April). Leadership in Customer Service: New Expectations, New Experiences. Retrieved October 1, 2005, from http://www.accenture.com/xdoc/ca/locations/canada/insights/studies/leade rship cust.pdf.

[8] Internet World Statistics. Retrieved September 30, 2005, from http://www.internetworldstats.com/.

[9] Epiphany, M. (2003, March 26). SMS for e-government? Smart Mobs. Retrieved from http://www.smartmobs.com/archive/2003/03/26/sms_for egover.html.

[10] ITU (2004). ITU Internet Reports 2004: The portable Internet. Retrieved May 17 2005, from http://www.itu.int/osg/spu/publications/ portableinternet/ExecSummFinal2 .pdf. 
[11] Fink, C., Mattoo, A. \& Rathindran, R. (2002, October). An Assessment of Telecommunications Reform in Developing Countries, 2-5, World Bank.

[12] Baskerville (2003). Messaging Market Forecasts. Retrieved October 4, 2005, from http://www.theinfoshop.com/pdf/ba8134.pdf.

[13] Mobinet Study. Retrieved May 22, 2005, from http://sellitontheweb.com/ezine/news0567.shtml.

[14] Yankee Group (2003, October 3). SMS to Find Footing Sooner. Retrieved October 4, 2005, from http://www.clickz.com/news/article.php/3087331.

[15] Burčík, V. (2002). SMS users content preferences: SMS users in Slovakia, EL\&T Ltd., Bratislava, Slovakia. Retrieved October 3, 2005, from http://www.acten.net/uploads/258/57/Burcik.doc.

[16] Asia Pacific Research Group (APRG) (2004, September). Asian Mobile Services Market - Outlook till 2007, p. 90. Retrieved October 2, 2005, from

http://www.researchandmarkets.com/reportinfo.asp?report id=39774.

[17] China Mobile Limited (2005). Business Review. Retrieved October 3, 2005, from http://www.chinamobilehk.com/op.php?menu=3.

[18] Chand, F. (2003, July 23). India's first matrimonial service on mobile. Retrieved October 4, 2005, from http://in.rediff.com/money/2003/jul/23mobilefirst.htm.

[19] Hudson H. E. (2005). Investing in Infrastructure: Increasing Internet Access in the Developing World, pp. 2-4. Retrieved October 6, 2005, from http://72.14.207.104/search?q=cache:f5mznyqfs28J:web.si.umich.ed u/tprc/papers/2004/355/TPRC04R2.pdf+(\%22internet+price $\% 22+\mathrm{OR}+\% 2$ 2internet $+\cos \mathrm{t} \% 22)+\mathrm{AND}++\% 22$ developing + countries $\% 22+\mathrm{AND}+\% 22 \mathrm{e}$ xpensive $\% 22 \& h \mathrm{l}=$ en.

[20] Mobile Media (2005, February). Global SMS statistics and update: massive revenues, growing worldwide, pp.16-17. Mobile Messaging analyst, Informa telecoms \& media.

[21] Rao M. (2004). Making New Technologies Work For Human Development. Human Development Report 2001. Retrieved October 7, 2005, from http://www.itu.int/wsis/docs/background/general/reports/ 26092001 undp.htm.

[22] Economist.com (2005, March 10). The real digital divide. Retrieved October 7, 2005, from http://www.economist.com/opinion/Printer Friendly.cfm?Story ID $=3742817$.

[23] Buckingham, (2002). Next Messaging - An Introduction to SMS, EMS, MMS. Mobile Streams. Retrieved January 27, 2006, from www.isty.uvsq.fr/ morin/ReseauMultimedia/An\%20Introduction $\% 20$ to $\%$ 20SMS, \%20EMS, \%20MMS.pdf.

[24] Buckingham, (2001). The Future of SMS - Introducing the Long messaging Service. Success 4 SMS. Retrieved January 27, 2006, from http://www.smszone.ru/technology/future/.

[25] Susanto T \& Goodwin R, An SMS based e-government model, Proceedings of the ICEIS conference, Cyprus 2006 (to be published). 